\title{
Utilization of Hypofractionated and Conventional Breast Radiotherapy in the State of Utah
}

\author{
Brandi R. Page ${ }^{1}$, Tom Belnap ${ }^{2}$, R. Christopher Bowen ${ }^{1}$, David K. Gaffney ${ }^{1} \&$ William T. Sause ${ }^{2}$ \\ ${ }^{1}$ University of Utah, Huntsman Cancer Institute, Salt Lake City, Utah, USA \\ ${ }^{2}$ Intermountain Health Care, Salt Lake City, Utah, USA \\ Correspondence: David Gaffney, Huntsman Cancer Institute, University of Utah, Salt Lake City, Utah, USA. Tel: \\ 1-801-581-8793. E-mail: david.gaffney@hci.utah.edu
}

Received: June 27, 2013 Accepted: August 2, 2013 Online Published: August 8, 2013

doi:10.5539/cco.v2n2p34 URL: http://dx.doi.org/10.5539/cco.v2n2p34

\begin{abstract}
Efficacy of hypofractionated (HF) radiotherapy (RT) in breast cancer has recently been established by randomized trials. We report patterns of care in Utah to identify how patient, tumor, and treatment characteristics may influence prescription patterns. Data from 1,588 patients from nine facilities with 18 providers were retrospectively collected. Conventionally fractionated (CF) RT was defined as $>19$ fractions with fractions $\leq$ 200cGy; HF was defined as $<19$ fractions with fractions $>200$ cGy. Partial breast irradiation (PBI) was defined as external beam RT to $3850 \mathrm{cGy}$ in 10 fractions. Patients considered eligible for HF were $>45$ years with breast separation $<25 \mathrm{~cm}$ and tumor size $<2 \mathrm{~cm}$ with negative nodes and margins. Analysis utilized Wilcoxon Rank Sum Tests and logistic regression. Of all patients, 83.2\% received $\mathrm{CF}, 12 \%$ received $\mathrm{HF}$, and $4.7 \%$ received PBI. Based on recent published guidelines, $53.5 \%$ of patients were eligible for HF. There were no significant differences with respect to laterality, tissue separation, or medical comorbidities. Calculated odds ratios (OR) for increased use of HF included age $(\mathrm{OR} 1.05, \mathrm{p}<0.001)$ and lower cancer stage (OR 3.75, $\mathrm{p}=0.002$ ). Use of HF strongly correlated with increased age, number of miles traveled to clinic (47.8 vs. 21), lower grade, less aggressive surgery, and less chemotherapy. HF RT utilization is increasing over time but only in a segment of eligible patients. We report on changes in practice patterns after recent publication of randomized trial data in an effort to bring awareness to underutilization of HF, and intend to track how this changes over time.
\end{abstract}

Keywords: breast cancer, hypofractionated radiotherapy, patterns of care

\section{Introduction}

\subsection{Background}

Conventionally fractionated (CF) whole breast radiotherapy, which typically involves five to six-and-a-half weeks of once daily, (five days a week) radiotherapy, has been a standard of care after lumpectomy since the publication of major randomized trials showing efficacy of breast conserving surgery plus radiotherapy to mastectomy. The National Surgical Adjuvant Breast and Bowel Project (NSABP)-B06 trial was first published in 1985 (Fisher et al., 1985) and updated in 2002 (Fisher et al., 2002), which used a five days a week, 25 fraction regimen of whole breast radiotherapy using conventional fractionation ( $\leq 200$ cGy per fraction). The problem with five to six and a half weeks of once daily radiotherapy is the burden of cost, emotional distress, and fatigue to patients undergoing prolonged daily treatment. Some reports reveal that an average of 20-30\% of North American women forego radiotherapy after receiving lumpectomy (Chuba \& Simon, 1997; Malin, Schuster, Kahn, \& Brook, 2002), or choose mastectomy over breast preservation (Tuttle, Habermann, Grund, Morris, \& Virnig, 2007) due to several factors, including age, psychological distress, quality of life concerns, and cost of undergoing prolonged daily radiotherapy (Dwyer, Hickey, Burmeister, \& Burmeister, 2010). Over the years, patient convenience and cost have been factors affecting some patients' ability to receive radiotherapy. One cohort study (Wallace, Priestman, Dunn, \& Priestman, 1993) reported on psychologic factors in women undergoing hypofractionated (HF) and conventionally fractionated (CF) RT. The women undergoing the HF regimen reported less anxiety, less transient weight change, and less depression compared to the CF group.

\subsection{Efficacy of Hypofractionated Radiotherapy}

More recently, a wealth of data have been published regarding the use of hypofractionated (HF) whole breast 
radiation after lumpectomy. Early published trials from France using data collected in the early 1980's and published in 1990 (Baillet et al., 1990) reported equal efficacy and no difference in complication rate between a 45 Gy treatment regimen in 25 fractions over 33 days versus a 23 Gy regimen in 4 fractions over 17 days. More recently from 2002-2010, published randomized trials from Canada (T. J. Whelan et al., 2002; T. J. Whelan et al., 2010) and the UK (Bentzen et al., 2008a; Yarnold et al., 2005) have shown equivalent survival and cosmesis between CF and HF whole breast RT. The START A (Bentzen et al., 2008a) trial also reported that both breast cancer and dose-limiting normal tissue responded similarly to change in radiotherapy fraction size, suggesting a potential benefit for patients receiving larger doses per fraction. More recent data is published regarding the use of partial breast irradiation (PBI), however, long-term followup of randomized trial data are still in process.

\subsection{Complicating Factors in Current Practice}

Despite published data, it is unknown how physicians are incorporating this information into their prescribing patterns. Some practice patterns in breast cancer radiotherapy have reflected new techniques long before randomized trial data are published, especially with regards to partial breast irradiation (PBI) (Husain et al., 2011), while other standards of care are not established in practice patterns until long after randomized trials have been published (Wilson \& Owen, 2005). Recent American Society of Therapeutic Radiation Oncology (ASTRO) guidelines for HF RT were published in 2011 (Smith et al., 2011) based on the available trial data to help guide physician practice. Reported factors that influence decisions whether a patient should get PBI, HF or CF radiotherapy include age, size of patient separation related to dose homogeneity, distance from home to facility, administration of chemotherapy, tumor characteristics, and patient comorbidities (Hennequin \& Azria, 2011; Hoopes et al., 2012; Smith et al., 2011). This study examines patient, facility, disease characteristics and patterns of care amongst the majority of radiation oncology facilities within the state of Utah over the formative years after major randomized trials have published in an effort to help guide quality improvement measures in the future.

\section{Method}

\subsection{Data Collection and Statistical Analysis}

Institutional Review Board approval was obtained from the facilities included. Data were collected on breast cancer patients undergoing radiation therapy between 2007 and 2010 at nine radiation therapy sites serving the majority of cancer patients in Utah. Data were collected from cancer registry records, radiation treatment planning records, and paper and electronic charts. These data included patient, tumor, and treatment characteristics. Patient data included age, number of traveling miles from residence to treatment facility, (calculated by number of miles from home address zip code to the treatment facility address), breast tissue separation, and comorbid conditions (cardiac comorbidities, asthma, diabetes, or lupus). Disease data included tumor stage, tumor grade, and laterality. Treatment data included radiotherapy dose and fractionation to whole breast and boost dose data, surgery (lumpectomy, mastectomy, reconstructive surgery), hormonal therapy, and chemotherapy. Data were collected and analyzed to examine which treatment, patient, facility, and disease factors were associated with increased frequency of HF treatment. Results were analyzed using Wilcoxon Rank Sum Test and logistic regression.

\subsection{Definitions of Treatment and Patient Eligibility}

HF RT was defined as a radiotherapy course of 12-19 fractions where each fraction was greater than 200 cGy. PBI was delivered via 3D conformal external beam RT in ten fractions, for a total of 38.5 Gy with fractions delivered twice daily (minimum of 6 hours between fractions). Because the institutions included in the analysis did not treat any patients with brachytherapy for PBI, only EBRT was reported. Conversely, CF RT was defined as a course of at least 20 fractions where each fraction was $200 \mathrm{cGy}$ or less. Each institution had the capability of performing external beam RT using CF, HF, or PBI, and patients were presented with the options per the clinician's preference. None of the institutions had a waiting list or waiting time for patients to get radiotherapy. Patients were categorized as "eligible" or "not eligible" for HF RT based on a combination of current ASTRO standards (Smith et al., 2011) and comorbidities which are known to impact wound healing (Chen, Obedian, \& Haffty, 2001; Kolluru, Bir, \& Kevil, 2012) (Morain \& Colen, 1990) or cosmesis (Taylor et al., 1995; Triedman, Osteen, \& Harris, 1990). Eligible patients for HF were defined as those with Age $>45$ years, Tumor $<2 \mathrm{~cm}$, breast separation $<25 \mathrm{~cm}$, negative nodes and negative surgical margins.

\section{Results}

\subsection{Patient Population}

Overall, 1,588 women treated with radiotherapy for breast cancer were identified from 2007-2010 in nine 
radiation facilities across Utah staffed by 15 providers. Of these, $1,322(83.3 \%)$ received CF, $191(12.0 \%)$ received HF, and 75 (4.7\%) received PBI. A total of 851 (53.5\%) patients were considered eligible for HF based on the above criteria. The mean radiotherapy dose received in the HF group was 40.4 Gy (median 40.05 Gy; range 40.05-42.72 Gy) with the median whole breast fraction size of 2.67 Gy (range 2.5-2.67 Gy per fraction). The median boost dose in the HF group was 10.0 Gy (range 0.0-12.5 Gy), with a median boost fraction size of 2.0 Gy per fraction (range if boost given was $2.0-3.44$ Gy per fraction). The mean radiotherapy dose in the CF group to the whole breast was $52.3 \mathrm{~Gy}$, with a median dose of $50 \mathrm{~Gy}$ (range 45-55 Gy) with a median whole breast fraction size of 2.0 Gy (range 1.8-2.0 Gy). The median boost dose in the CF group was $10 \mathrm{~Gy}$ (range 0-20 Gy) with a median boost fraction size of 2.0 Gy per fraction (if boost given, range was 1.8-2.0 Gy per fraction).

\subsection{Data Analysis of Patient Characteristics}

Analysis of patient data revealed HF patients with significantly older average age for patients (64 years HF; 57 years $\mathrm{CF} ; \mathrm{p}=<0.0001)$, with odds ratio (OR) of 1.05 associated with increased use of HF RT. They also had a significantly longer average travel distance from their home to the treating facility (47.8 miles HF vs. 21 miles $\mathrm{CF} ; \mathrm{p}=0.0068$ ). No significant differences were found between patients receiving $\mathrm{CF}$ compared to $\mathrm{HF}$ with regard to laterality (left or right-sided breast), comorbid conditions (lupus, diabetes, cardiac comorbidities), or tissue separation as calculated at the beam entrance through the deep chest wall (CF average $22.5 \mathrm{~cm}$ and $\mathrm{HF}$ $22.3 \mathrm{~cm})$.

\subsection{Data Analysis of Disease Characteristics}

Regarding disease characteristics, patients receiving HF had smaller tumor size $(\mathrm{p}=0.004)$, and were less likely to have positive lymph nodes $(\mathrm{p}<0.0001)$. Odds ratios were calculated on factors associated with increased use of $\mathrm{HF}$; these include lower cancer stage (OR 3.75, $\mathrm{p}=0.002$ ) and patients with grade 3 disease were less likely to receive $\mathrm{HF}(\mathrm{OR} 0.67, \mathrm{p}=0.045)$.

\subsection{Data Analysis of Treatment Characteristics}

Treatment analysis revealed HF patients were more likely to have a lumpectomy ( $\mathrm{p}=0.0003$ ) with significantly less patients undergoing mastectomy ( $9 \% \mathrm{HF}$ vs. $21 \% \mathrm{CF}$ ). The patients receiving HF RT after mastectomy were predominantly treated in one of the nine facilities. For radiotherapy treatment, $\mathrm{CF}$ patients were more likely to have a boost to their primary site $(\mathrm{p}<0.0001)$ and for systemic treatment, CF patients more likely to have chemotherapy (mean CF: 0.38, HF: 0.1917, p<0.0001). Results are summarized in Table 1.

Table 1. Patient, disease, and treatment characteristics in hypofractionated (HF) and conventionally fractionated (CF) Groups

\begin{tabular}{|c|c|c|c|}
\hline Variable & HF & $\mathrm{CF}$ & p value \\
\hline Mean age (yrs) & 65 & 57 & $<.0001$ \\
\hline Average distance from home to facility (miles) & 47.8 & 21 & 0.0068 \\
\hline$\%$ pts with grade 3 tumors & $15.5 \%$ & $21.5 \%$ & OR $0.67, p=0.045$ \\
\hline$\%$ pts who had lumpectomy (remaining had mastectomy) & $83 \%$ & $71 \%$ & 0.0001 \\
\hline$\%$ pts who underwent breast reconstructive surgery & $9 \%$ & $21 \%$ & $<.0001$ \\
\hline$\%$ pts who received systemic chemotherapy (non-hormonal) & $19 \%$ & $38 \%$ & $<.0001$ \\
\hline Median of whole breast fractions (range) & 15 & 25 & $<.0001$ \\
\hline Median whole breast dose and range (Gy) & $40.05(40.05-42.72)$ & $50.0(45.0-55.0)$ & $<.0001$ \\
\hline Median boost dose and range (Gy) & $10(0.0-12.5)$ & $10(0.0-20.0)$ & \\
\hline Median fraction size for whole breast and range (Gy) & $2.67(2.5-2.67)$ & $2.0(1.8-2.0)$ & \\
\hline Percent of all patients receiving breast radiotherapy & HF: $12 \%$ & CF: $83.3 \%$ & PBI: $4.7 \%$ \\
\hline Percent of patients eligible for $\mathrm{HF}$ & HF or PBI: $19.3 \%$ & & CF: $80.7 \%$ \\
\hline
\end{tabular}

As shown in Table 1, in total, there were $12 \%$ of patients receiving HF, $83.3 \%$ of patients receiving $\mathrm{CF}$, and $4.7 \%$ of patients receiving Partial Breast Irradiation (PBI). A total of $19.3 \%$ of patients that were eligible for HF, received either HF or PBI, and $80.7 \%$ of them received $\mathrm{CF}$.

$\mathrm{OR}=$ odds ratio, $\mathrm{PBI}=$ partial breast irradiation 


\subsection{Data Analysis of Prescription Patterns by Facility}

The vast difference in use of HF between facilities was due to provider preference. All facilities had the availability of performing external beam radiotherapy with the three different radiotherapy techniques described, CF, HF and PBI. Details regarding the facility and providers were not included in the study because the participating providers agreed to participate only if they were not individually identifiable.

\section{Discussion}

Clearly the use of HF, or shortened course radiotherapy has become more popular since the publication of major randomized trials showing its efficacy to conventionally fractionated, protracted radiotherapy. However, there continues to be a lag in prescription patterns for patients considered to be clinically eligible for shorter courses of radiotherapy based on publication of randomized trials. Factors that may impact patient quality of life, such as age and travel requirements may impact the decision of whether to prescribe HF as reported previously by Wallace (Wallace et al., 1993). Both of these factors were strongly associated with prescriptions for HF in our study and confirm our hypothesis that patient characteristics are associated with prescribers' willingness to prescribe HF radiotherapy. As confirmed in Figure 1, utilization of HF by facility varied significantly between facilities staffed with different providers. This may reflect a function of provider preference and reluctance among some providers to incorporate new data into practice in situations where traditional treatment methods have previously been very effective. Adaptation of incorporating new data into practice is a topic that deserves further investigation, particularly with regard to why providers will or will not prescribe new treatments despite the presence of new data. Other reasons for differing prescription patterns between clinicians may be due to provider preference, long term clinic experience, patient population, patient preference, funding sources, frequency of continuing medical education, or provider beliefs about adequacy of long term data followup.

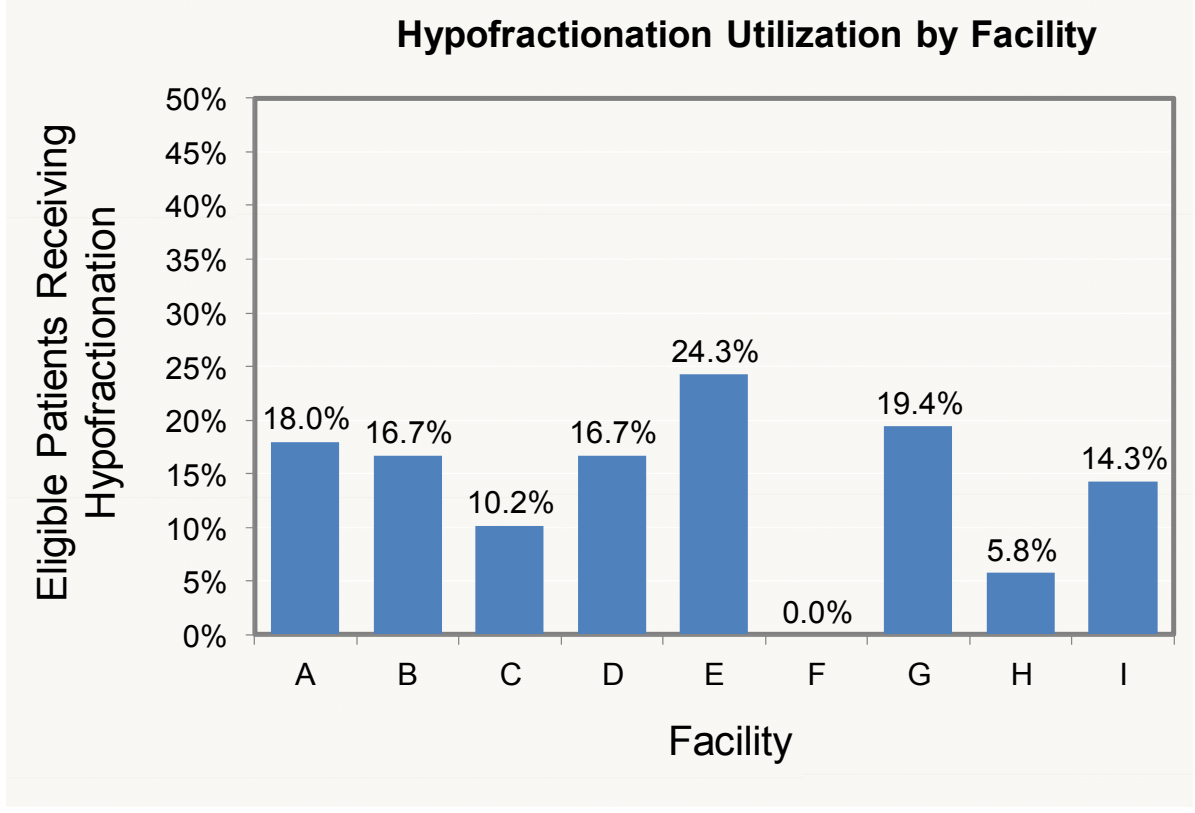

Figure 1. Hypofractionation utilization by facility

Figure 1 shows utilization of HF by facility for all breast cancer patients. There were significant differences between institutional practice in the use of $\mathrm{HF}$ in the nine facilities, with a range of $0 \%$ of patients getting $\mathrm{HF}$ in one facility, to $24.3 \%$ in another $(\mathrm{p}<0.001)$.

While actual numeric cost of treatment was not included in our results, socioeconomic aspects of deciding on a $\mathrm{CF}$ or HF regimen for patients may be associated with cost. Cost, both to the patient and to the facility, is a potential factor that could be considered with socioeconomic factors in future studies. In terms of potential cost to the patient in our analysis, patients receiving HF had a significantly longer commute to the treating facility from their home (Table 1), which may reflect the provider's willingness to consider HF in situations where patient cost or burden of treatment is higher. On an institutional level, though none of the facilities included in 
our analysis were from severely underserved regions, the prescription patterns for HF could reflect the providers' willingness to consider HF more often in institutions with a greater number of patients needing treatment. Previous analyses from Australia (Dwyer et al., 2010) examining the institutional cost of HF versus CF regimens, have shown that at least an extra fourteen patients could be treated each month with HF regimens and health related costs could be reduced by at least $24 \%$.

As another option for patients who have received lumpectomy, PBI is becoming much more popular for patients with early stage breast cancers. However, as long term randomized trial data are still awaiting publication, local control of disease, overall cost, cosmesis, and efficacy (Suh, Pierce, Vicini, \& Hayman, 2005) still remain long term questions. The PBI subset in our analysis was included simply to include a competing radiotherapy modality for patients that would have also been eligible for HF radiotherapy. As Figure 2 illustrates, the percentage of patients receiving shorter courses of radiotherapy, either with PBI or HF increased significantly over the four year period of analysis. The time period for this analysis (2007-2010) was chosen in order to investigate the impact of recently published long-term data from major randomized trials from 2005 through 2008 (Bentzen et al., 2008a, 2008b; Eldeeb, Awad, \& Elhanafy, 2012; Hoopes et al., 2012; Smith et al., 2011 ; T. J. Whelan et al., 2010; Yarnold et al., 2005) to identify factors that may impact whether eligible patients receive HF RT.

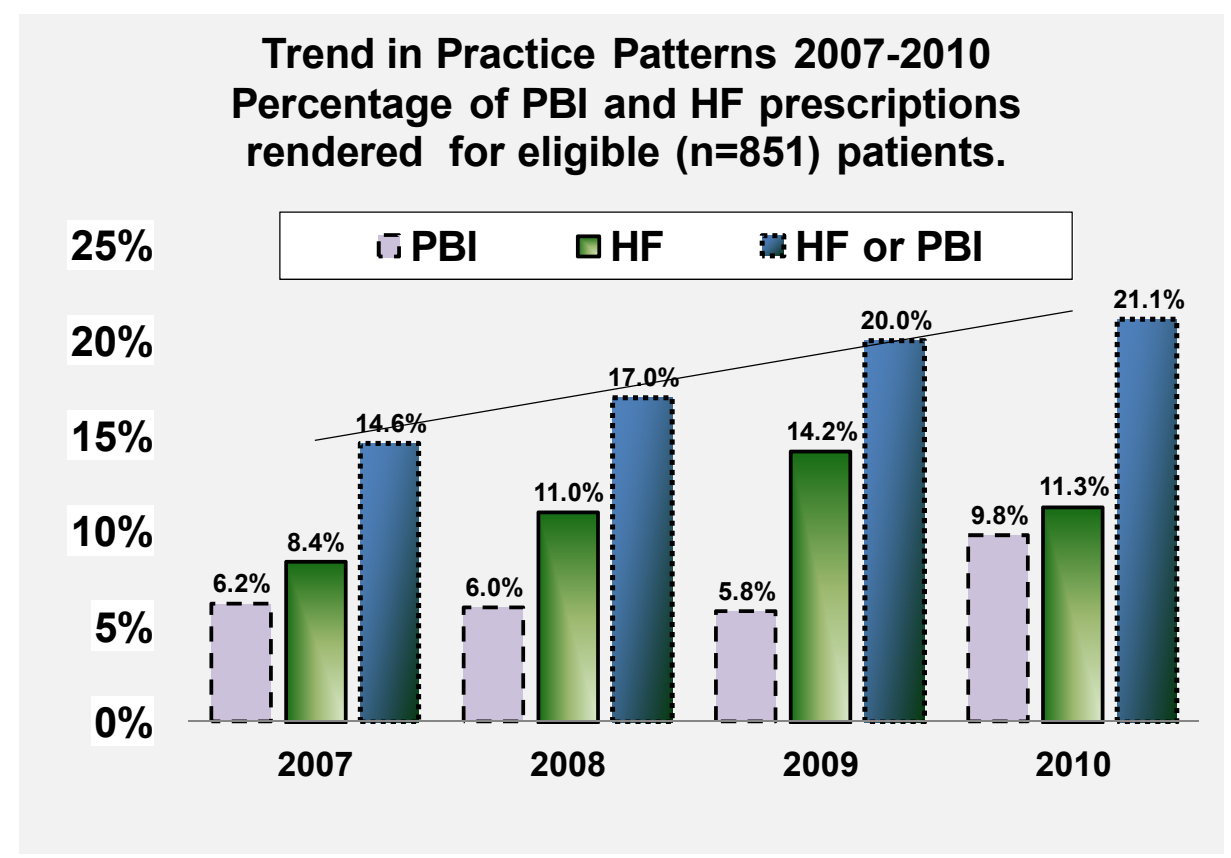

Figure 2. Trend in practice patterns

Figure 2 illustrates the increasing trend of using hypofractionated techniques (including HF and PBI) among eligible patients over the study period. The overall use of either PBI or HF regimens for eligible patients increased significantly from $14.6 \%$ in 2007 to and $21.1 \%$ in $2010(\mathrm{p}<0.001)$.

In terms of disease and treatment characteristics, tumor grade did affect prescription frequency in Utah, this may be due to the long term follow-up data from the Canadian trial (T. J. Whelan et al., 2010) showing a much higher recurrence in women with grade 3 breast cancers undergoing HF (42.5 Gy in 16 fractions $-15.6 \%)$ vs. CF (50 Gy in 25 fractions-4.6\%) ( $\mathrm{p}=0.01)$. In our series, the vast majority of women who underwent any reconstructive surgery did not get HF prescriptions; this could be due to these patients receiving mastectomy, and potential reluctance on the part of the surgeon and radiation oncologist to subject the tissues to potential microvascular compromise. Though there was a limited population of post mastectomy patients receiving HF in the START trial (Bentzen et al., 2008b), little data exist on this topic and more studies should be completed to further outline the appropriateness of postmastectomy HF RT. Though a few international retrospective reviews report safety and efficacy of post mastectomy RT to include a supraclavicular field (Pinitpatcharalert et al., 2011; Shahid et al., 2009) in developing countries, there is likely considerable fear in prescribing a dose of radiotherapy that may 
exceed brachial plexus tolerance (Henriques de Figueiredo et al., 2010). Radiotherapy dose, fraction size, and whether or not boost was prescribed also reflected published data from the START and Whelan trials; where the majority of HF patients in our series received either no lumpectomy cavity boost or received 10 Gy boost given in 2.0 Gy fractions (Table 1).

Given the evidence that decreasing amount of fractions delivered decreases burden on the health care system (Dwyer et al., 2010) and the patient (Wallace et al., 1993), we believe there is sufficient evidence to suggest implementation of hypofractionation in appropriate patients will improve access to care and improve patient experience.

This report represents a state-wide analysis on patterns of care in the formative years directly following the publication of major randomized trials in hypofractionated breast radiotherapy. This is the first large report of patterns of care in a statewide inter-facility fashion that identifies factors that may influence the rate of HF RT prescriptions. Use of HF RT is increasing over the study period, but is still only being utilized in a small group of eligible patients. Institutional data have been shared in a blinded fashion, with the idea that awareness of patterns of care may remind physicians of the opportunities to consider prescribing shorter courses of radiotherapy when clinically appropriate. Our plan is to re-analyze patterns of care as more scientific outcomes become available regarding HF. As long-term data from PBI and HF studies are published, prescription patterns are likely to continue to evolve. In addition, following actual patterns of care may be useful to increase awareness of how quickly physicians incorporate data into current clinical practice. These data can be used to identify factors that may promote adaptation to up-to-date randomized trial information to improve efficiency, quality of care, and patient experience.

\section{References}

Albert, J. M., \& Das, P. (2012). Quality assessment in oncology. Int J Radiat Oncol Biol Phys, 83(3), 773-781. http://dx.doi.org/10.1016/j.jijrobp.2011.12.079

Baillet, F., Housset, M., Maylin, C., Boisserie, G., Bettahar, R., Delanian, S., \& Habib, F. (1990). The use of a specific hypofractionated radiation therapy regimen versus classical fractionation in the treatment of breast cancer: a randomized study of 230 patients. Int J Radiat Oncol Biol Phys, 19(5), 1131-1133. http://dx.doi.org/10.1016/0360-3016(90)90216-7

Bentzen, S. M., Agrawal, R. K., Aird, E. G., Barrett, J. M., Barrett-Lee, P. J., Bliss, J. M., ... Yarnold, J. R. (2008a). The UK Standardisation of Breast Radiotherapy (START) Trial A of radiotherapy hypofractionation for treatment of early breast cancer: a randomised trial. Lancet Oncol, 9(4), 331-341. http://dx.doi.org/10.1016/S1470-2045(08)70077-9

Bentzen, S. M., Agrawal, R. K., Aird, E. G., Barrett, J. M., Barrett-Lee, P. J., Bliss, J. M., ... Yarnold, J. R. (2008b). The UK Standardisation of Breast Radiotherapy (START) Trial B of radiotherapy hypofractionation for treatment of early breast cancer: a randomised trial. Lancet, 371(9618), 1098-1107. http://dx.doi.org/10.1016/S0140-6736(08)60348-7

Chen, A. M., Obedian, E., \& Haffty, B. G. (2001). Breast-conserving therapy in the setting of collagen vascular disease. Cancer J, 7(6), 480-491.

Chuba, P. J., \& Simon, M. S. (1997). Trends in primary surgical and radiation therapy for localized breast cancer in the Detroit Metropolitan area 1973-1992. Int J Radiat Oncol Biol Phys, 38(1), 103-107. http://dx.doi.org/10.1016/S0360-3016(96)00615-3

Dwyer, P., Hickey, B., Burmeister, E., \& Burmeister, B. (2010). Hypofractionated whole-breast radiotherapy: impact on departmental waiting times and cost. J Med Imaging Radiat Oncol, 54(3), 229-234. http://dx.doi.org/10.1111/j.1754-9485.2010.02163.x

Eldeeb, H., Awad, I., \& Elhanafy, O. (2012). Hypofractionation in post-mastectomy breast cancer patients: seven-year follow-up. Med Oncol. http://dx.doi.org/10.1007/s12032-012-0192-1

Fisher, B., Anderson, S., Bryant, J., Margolese, R. G., Deutsch, M., Fisher, E. R., ... Wolmark, N. (2002). Twenty-year follow-up of a randomized trial comparing total mastectomy, lumpectomy, and lumpectomy plus irradiation for the treatment of invasive breast cancer. $N$ Engl J Med, 347(16), 1233-1241. http://dx.doi.org/10.1056/NEJMoa022152

Fisher, B., Bauer, M., Margolese, R., Poisson, R., Pilch, Y., Redmond, C., ... Russell, I. (1985). Five-year results of a randomized clinical trial comparing total mastectomy and segmental mastectomy with or without radiation in the treatment of breast cancer. $N$ Engl $J$ Med, 312(11), 665-673. 
http://dx.doi.org/10.1056/NEJM198503143121101

Freedman, G. M. (2012). Hypofractionated radiation therapy in the treatment of early-stage breast cancer. Curr Oncol Rep, 14(1), 12-19. http://dx.doi.org/10.1007/s11912-011-0207-7

Grol, R., \& Grimshaw, J. (1999). Evidence-based implementation of evidence-based medicine. Jt Comm J Qual Improv, 25(10), 503-513.

Hassett, M. J., Hughes, M. E., Niland, J. C., Ottesen, R., Edge, S. B., Bookman, M. A., ... Weeks, J. C. (2008). Selecting high priority quality measures for breast cancer quality improvement. Med Care, 46(8), 762-770. http://dx.doi.org/10.1097/MLR.0b013e318178ead3

Hennequin, C., \& Azria, D. (2011). The future of breast cancer radiotherapy: From one size fits all to taylor-made treatment. Cancer Radiother, 15(6-7), 455-459. http://dx.doi.org/10.1016/j.canrad.2011.05.008

Henriques de Figueiredo, B., Huchet, A., Dejean, C., Mamou, N., Sargos, P., Loiseau, H., \& Kantor, G. (2010). Cancer Radiother, 14(4-5), 405-410. http://dx.doi.org/10.1016/j.canrad.2010.03.012

Hoopes, D. J., Kaziska, D., Chapin, P., Weed, D., Smith, B. D., Hale, E. R., \& Johnstone, P. A. (2012). Patient Preferences and Physician Practice Patterns Regarding Breast Radiotherapy. International Journal of Radiation Oncology*Biology*Physics, 82(2), 674-681. http://dx.doi.org/10.1016/j.ijrobp.2010.11.077

Husain, Z. A., Mahmood, U., Hanlon, A., Neuner, G., Buras, R., Tkaczuk, K., \& Feigenberg, S. J. (2011). Accelerated partial breast irradiation via brachytherapy: a patterns-of-care analysis with ASTRO consensus statement groupings. Brachytherapy, 10(6), 479-485. http://dx.doi.org/10.1016/j.brachy.2011.05.001

Kolluru, G. K., Bir, S. C., \& Kevil, C. G. (2012). Endothelial dysfunction and diabetes: effects on angiogenesis, vascular remodeling, and wound healing. Int $J$ Vasc Med, 2012, 918267. http://dx.doi.org/10.1155/2012/918267

Livi, L., Buonamici, F. B., Simontacchi, G., Scotti, V., Fambrini, M., Compagnucci, A., ... Biti, G. (2010). Accelerated partial breast irradiation with IMRT: new technical approach and interim analysis of acute toxicity in a phase III randomized clinical trial. Int $J$ Radiat Oncol Biol Phys, 77(2), 509-515. http://dx.doi.org/10.1016/j.ijrobp.2009.04.070

Magee, B., Swindell, R., Harris, M., \& Banerjee, S. S. (1996). Prognostic factors for breast recurrence after conservative breast surgery and radiotherapy: results from a randomised trial. Radiother Oncol, 39(3), 223-227.

Malin, J. L., Schuster, M. A., Kahn, K. A., \& Brook, R. H. (2002). Quality of breast cancer care: what do we know? J Clin Oncol, 20(21), 4381-4393.

Mannino, M., \& Yarnold, J. R. (2009). Shorter fractionation schedules in breast cancer radiotherapy: clinical and economic implications. Eur J Cancer, 45(5), 730-731. http://dx.doi.org/10.1016/j.ejca.2009.01.024

McCormick, B. (2012). Partial breast radiation for early-stage breast cancer. Curr Opin Obstet Gynecol, 24(1), 31-37. http://dx.doi.org/10.1097/GCO.0b013e32834d4aaf

Morain, W. D., \& Colen, L. B. (1990). Wound healing in diabetes mellitus. Clin Plast Surg, 17(3), 493-501.

Pinitpatcharalert, A., Chitapanarux, I., Euathrongchit, J., Tharavichitkul, E., Sukthomya, V., \& Lorvidhaya, V. (2011). A retrospective study comparing hypofractionated radiotherapy and conventional radiotherapy in postmastectomy breast cancer. J Med Assoc Thai, 94(Suppl 2), S94-102.

Shahid, A., Athar, M. A., Asghar, S., Zubairi, T., Murad, S., \& Yunas, N. (2009). Post mastectomy adjuvant radiotherapy in breast cancer: a comparision of three hypofractionated protocols. J Pak Med Assoc, 59(5), 282-287.

Smith, B. D., Bentzen, S. M., Correa, C. R., Hahn, C. A., Hardenbergh, P. H., Ibbott, G. S., ... Haffty, B. G. (2011). Fractionation for whole breast irradiation: an American Society for Radiation Oncology (ASTRO) evidence-based guideline. Int $J$ Radiat Oncol Biol Phys, 81(1), 59-68. http://dx.doi.org/10.1016/j.ijrobp.2010.04.042

Suh, W. W., Pierce, L. J., Vicini, F. A., \& Hayman, J. A. (2005). A cost comparison analysis of partial versus whole-breast irradiation after breast-conserving surgery for early-stage breast cancer. Int $J$ Radiat Oncol Biol Phys, 62(3), 790-796. http://dx.doi.org/10.1016/j.ijrobp.2004.10.039

Taylor, M. E., Perez, C. A., Halverson, K. J., Kuske, R. R., Philpott, G. W., Garcia, D. M., ... Rush, C. (1995). Factors influencing cosmetic results after conservation therapy for breast cancer. Int J Radiat Oncol Biol 
Phys, 31(4), 753-764.

Triedman, S. A., Osteen, R., \& Harris, J. R. (1990). Factors influencing cosmetic outcome of conservative surgery and radiotherapy for breast cancer. Surg Clin North Am, 70(4), 901-916.

Tuttle, T. M., Habermann, E. B., Grund, E. H., Morris, T. J., \& Virnig, B. A. (2007). Increasing use of contralateral prophylactic mastectomy for breast cancer patients: a trend toward more aggressive surgical treatment. J Clin Oncol, 25(33), 5203-5209. http://dx.doi.org/10.1200/JCO.2007.12.3141

Valachis, A., Mauri, D., Polyzos, N. P., Mavroudis, D., Georgoulias, V., \& Casazza, G. (2010). Partial breast irradiation or whole breast radiotherapy for early breast cancer: a meta-analysis of randomized controlled trials. Breast J, 16(3), 245-251. http://dx.doi.org/10.1111/j.1524-4741.2010.00905.x

Wallace, L. M., Priestman, S. G., Dunn, J. A., \& Priestman, T. J. (1993). The quality of life of early breast cancer patients treated by two different radiotherapy regimens. Clin Oncol (R Coll Radiol), 5(4), 228-233.

Whelan, T., MacKenzie, R., Julian, J., Levine, M., Shelley, W., Grimard, L., ... Szechtman, B. (2002). Randomized trial of breast irradiation schedules after lumpectomy for women with lymph node-negative breast cancer. J Natl Cancer Inst, 94(15), 1143-1150.

Whelan, T. J., Pignol, J. P., Levine, M. N., Julian, J. A., MacKenzie, R., Parpia, S., ... Freeman, C. (2010). Long-term results of hypofractionated radiation therapy for breast cancer. $N$ Engl J Med, 362(6), 513-520. http://dx.doi.org/10.1056/NEJMoa0906260

Wilson, J. F., \& Owen, J. (2005). Quality research in radiation oncology: a self-improvement initiative 30 years ahead of its time? J Am Coll Radiol, 2(12), 1001-1007. http://dx.doi.org/10.1016/j.jacr.2005.06.009

Yarnold, J., Ashton, A., Bliss, J., Homewood, J., Harper, C., Hanson, J., ... Owen, R. (2005). Fractionation sensitivity and dose response of late adverse effects in the breast after radiotherapy for early breast cancer: long-term results of a randomised trial. Radiother Oncol, 75(1), 9-17. http://dx.doi.org/10.1016/j.radonc.2005.01.005

\section{Copyrights}

Copyright for this article is retained by the author(s), with first publication rights granted to the journal.

This is an open-access article distributed under the terms and conditions of the Creative Commons Attribution license (http://creativecommons.org/licenses/by/3.0/). 